\title{
Europtics: an international master in optics and photonics
}

François Flory, Michel Lequime, Hans Eichler, Mario Martinelli, Heinar Schmitt, et al.

François Flory, Michel Lequime, Hans Eichler, Mario Martinelli, Heinar Schmitt, Andrea Melloni, Michael Paul, "Europtics: an international master in optics and photonics," Proc. SPIE 9664, Ninth International Topical Meeting on Education and Training in Optics and Photonics, 966415 (24 October 2005); doi: 10.1117/12.2207788

Event: Ninth International Topical Meeting on Education and Training in Optics and Photonics, 2005, Marseille, France 


\section{Ref ETOP103}

\section{Europtics : an international master in Optics and Photonics}

François Flory, Michel Lequime, Hans Eichler, Mario Martinelli, Heinar Schmitt, Andrea Melloni, Michael Paul

\section{Abstracts}

The Ecole Généraliste d'Ingénieurs de Marseille (France), the Politecnico di Milano (Italy) and the Technische Universität Berlin (Germany) have joined forces within a new academic consortium (EUROPTICS) to set up a highly innovative top-quality European Masters programme in advanced optics for the information society.

The Course all in English aims to provide high-level theoretical and technical competence in the fields of optics, photonics and optoelectronics. Students on the programme have a unique opportunity to study within a truly multicultural environment, by spending time at each participating institution in turn: Marseille; Berlin and Milan. The organization and the pedagogy will be presented.

\section{Summary}

Top level opticians and photonicians must obviously be capable in working in a multidisciplinary and multicultural environment. They are enriched by participating in research in a laboratory. They must also be aware of the challenges and organization of the companies. These three objectives are reached in the Europtics master thanks to an original organization of the studies in three different countries, thanks to course taught by high level researchers close to their laboratory, and thanks to an internship in a professional environment. This was our motivation for setting up an original European master.

The Ecole Généraliste d'Ingénieurs de Marseille (France), Technische Universität Berlin (Germany) and the Politecnico di Milano (Italy) decided in 2001 to offer a joint Programme of study leading to the joint award by the three institutions of the European Master of Science in Optics for the Information Society. The master was launched in 2002.

We choose to propose this master to students from different countries and different cultures during the whole course. The program was launched with students from the three partner institutions and is now extended to students from other institutions and countries.

1. Organization of the studies

They have at least four years of studies in physics. The students are all together during the course, apart the training period. They spend 2 to 3 months in France, in Germany and in Italy, their training period lasting 4 months taking place in any country. As the students compose a small group, the relations between them are strong. At the beginning of the course they benefit from an intercultural meeting. The courses are taught in English and 20 to 30 hours of French language, German language and Italian language are proposed in the different countries.

During their stay in Marseille, in strong interaction with researchers, they have to perform a bibliography on a research problem.

During their stay in Berlin they have to work with a company on a small project.

During their stay in Milan they are involved in an applied research work.

So they have both a first experience in industry and in a research laboratory. This experience is reinforced by the 4 month training period.

The courses are roughly divided in optical components and electromagnetism, lasers and optical memories and optical telecommunications. These three parts correspond to particular competences respectively at the Fresnel Institute in France, the optics department in Germany and the Corecom in Italy. 
A joint committee comprising two nominees from each Institution plus a Master Director from the Coordinating Institute is in charge of

(i) recruitment and admission of students;

(ii) operation of the course (e.g. staffing, timetabling, accommodation);

(iii) management of assessment including assessment requirements;

(iv) identification of course-related resource needs;

(v) production and maintenance of comprehensive student course documentation;

(vi) monitoring and evaluation of the course and follow up actions;

(vii) approval of the annual course monitoring report(s) for the course (such reports shall be forwarded to the appropriate staff at the Institutions);

(viii) recommendations relating to initial approval and subsequent modification of courses and regulations;

(x) recommendations on the level of tuition fees and the distribution of tuition fees and share of student load;

(xi) decision on the composition of the Examining board.

The joint committee produces an annual report.

One of the nominee from each Partner acts as Local Director.

2. prerequisites

Full-time MSc students are expected to have at least a Bachelorl's degree or the equivalent qualification in Physics, Applied Physics or Electrical Engineering.

They must fulfil the following conditions :

- $\quad$ a certificate of proficiency in the English language (except for native speakers) :

* TOEIC : 750 points min. or

* Computer-based TOEFL : 215 points min. or

- $\quad$ sufficient results at the GRE general test and subject test in physics

3. Assessments

The grades are provided by the institution where the course takes place, following the local regulation. The examination board composed of teachers from the three partner institutions validates the marks submitted by each Partner Institution, and recommends to the Joint Committee the award of the degree.

4. Employment

We have only a small experience on the employments of the Europtics graduates. The first are employed in companies where they performed their internship or start a PhD thesis. The companies are all concerned with the international market. 